opportunity to study effectiveness and safety of bDMARDs, including bsDMARDs in AS.

Acknowledgements: Partly funded by a grant from NordForsk

Disclosure of Interest: B. Glintborg Grant/research support from: abbvie, K. Chatzidionysiou: None declared, J. Askling Grant/research support from: AbbVie, Eli Lilly, Janssen, Merck, Pfizer, Roche, UCB, Samsung, K. Aaltonen Speakers bureau: AbbVie, BMS, Janssen, MSD, Pfizer, Roche, UCB, E. Kristianslund: None declared, B. Gudbjornsson Grant/research support from: Actavis, Celgene, MSD, Pfizer, D. Nordström Speakers bureau: AbbVie, BMS, Lilly, MSD, Novartis, Pfizer, Roche, UCB, M. Hetland Grant/research support from: Orion, BMS, AbbVie, Biogen, Pfizer, MSD, L. Dreyer Speakers bureau: MSD, UCB, Janssen Pharmaceuticals, L. E. Kristensen Speakers bureau: Pfizer, AbbVie, Biogen, Amgen, UCB, Celegene, BMS, MSD, Novartis, Eli Lilly, Janssen pharmaceuticals, T. Jørgensen Speakers bureau: AbbVie, Roche, Novartis, UCB, Biogen, K. Eklund: None declared, G. Grondal: None declared, S. Ernestam: None declared, J. Joensuu Grant/research support from: Pfizer, T. Kvien Speakers bureau: AbbVie, Biogen, BMS, Boehringer Ingelheim, Celltrion, Eli Lilly, Epirus, Janssen, MerckSerono, MSD, Mundipharma, Novartis, Oktal, Orion Pharma, Hospira/Pfizer, Roche, Sandoz, UCB, E. Lie Speakers bureau: AbbVie, Celgene, Hospira, Pfizer, K. Fagerli: None declared, A. J. Geirsson: None declared, H. Jonsson: None declared, L. Jacobsson Consultant for: Abbvie, Celegen, MSD, Novartis, UCB DOI: 10.1136/annrheumdis-2017-eular.1891

\section{THU0362 EFFECT OF BIOTECHNOLOGICAL DRUGS ON EXTRA-ARTICULAR MANIFESTATIONS OF ANKYLOSING SPONDYLITIS: SYSTEMATIC REVIEW}

A.L.R. Pinto ${ }^{1}$, C.V. Pessoa ${ }^{1,2}$, L.S. Inês ${ }^{1,3} \cdot{ }^{1}$ Faculty of Health Sciences, University of Beira Interior, Covilhã; ${ }^{2}$ Rheumatology, Local Health Unit of Guarda, Guarda; ${ }^{3}$ Rheumatology, Coimbra Hospital and Universitary Centre, Coimbra, Portugal

Background: Treatment with biotechnological agents (infliximab, etanercept, adalimumab, golimumab and certolizumab pegol) in ankylosing spondylitis (AS) is effective. However, evidence regarding the potential efficacy of these anti-TNF drugs in the extra-articular manifestations of ankylosing spondylitis, namely in uveitis (UV), inflammatory bowel disease (IBD) and dactylitis is scarce.

Objectives: To analyze evidence on efficacy of anti-TNF drugs approved for AS treatment in UV, IBD and dactylitis associated with AS.

Methods: A systematic literature review was performed using the PubMed and Cochrane Library databases. Randomized controlled trials (RCT), metaanalyzes and observational studies (OS) reporting efficacy of anti-TNF agents in extra-articular manifestations of AS were included.

Results: Fifty studies were included (seventeen RCTs, six meta-analyses and twenty seven observational studies). From the RCT we extracted the results presented in Table 1 for uveitis and in Table 2 for IBD. None reported results for dactylitis. Of the meta-analyzes included, only one presents results. These one shows that the incidence of uveitis is lower in patients taking etanercept than placebo (incidence of 8.6 and 19.3 per 100 patients per year, respectively; $p$ value $=0.03$ ). In OS comparing different drugs, in one the risk of developing uveitis was 1.9 times higher in patients under etanercept compared to those under adalimumab ( $p$ value $=0.0223$ ) and a risk similar to those under infliximab and those under adalimumab. In another we have a percentage of patients with uveitis, during the course of the study, under etanercept of $8.0 \%$ and under infliximab of $4.0 \%$. In the OS, the percentage of patients with UV events with infliximab was in a range of $0.0 \%>3.1 \%$ with a follow-up interval between 2 years and 5 years; with etanercept was $0.9 \%>29.6 \%$ and a follow-up time interval between 12 weeks to 7 years; with adalimumab there is only one study with duration of 2 years reporting $3.9 \%$ UV events. Regarding IBD reported in OS, there was 3.7\% $>7.7 \%$ patients with events under treatment with etanercept over a follow-up time of 3.2-7 years; with adalimumab only a 2 -year study reported IBD in $0.6 \%$ of cases. We did not find results regarding for other extra-articular manifestations or anti-TNF drugs.

Table 1. Percentage of patients with events of uveitis on Randomized Controlled Trials

\begin{tabular}{lcc}
\hline Uveitis & \multicolumn{2}{c}{ Randomized Controlled Trials } \\
\cline { 2 - 3 } & \% patients with events under therapy \% patients with events under placebo \\
\hline Infliximab & 2,9 & 8,6 \\
Etanercept & 1,1 & 3,5 \\
Adalimumab & No results & No results \\
Golimumab & No results & No results \\
Certolizumab pegol & 0,9 & 2,8 \\
\hline
\end{tabular}

Table 2. Percentage of patients with events of inflammatory bowel disease on Randomized Controlled Trials

\begin{tabular}{lcc}
\hline Inflammatory Bowel & \multicolumn{2}{c}{ Randomized Controlled Trials } \\
\cline { 2 - 4 } Disease & \% patients with events under therapy \% patients with events under placebo \\
\hline Infliximab & No results & No results \\
Etanercept & 1,1 & 0,7 \\
Adalimumab & 1,0 & 0,0 \\
Golimumab & No results & No results \\
Certolizumab pegol & 0,0 & 0,9
\end{tabular}

Conclusions: Efficacy of anti-TNF drugs on extra-articular manifestations of AS

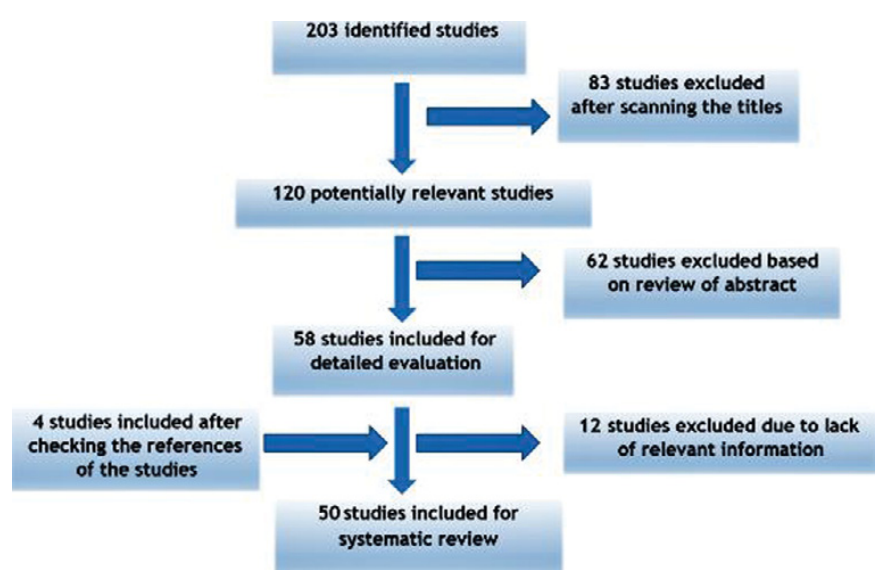

is under-reported in RCTs. Available data suggests possible efficacy of infliximab, adalimumab and certolizumab in UV, and of certolizumab in IBD. No evidence is available about anti-TNF efficacy in AS-associated dactylitis. Future studies with anti-TNF drugs should better report on extra-articular manifestations in AS.

Disclosure of Interest: None declared

DOI: 10.1136/annrheumdis-2017-eular.5138

\section{THU0363 IMPACT OF ADALIMUMAB ON CLINICAL OUTCOMES, HEALTHCARE RESOURCE UTILIZATION AND SICK LEAVES IN ANKYLOSING SPONDYLITIS PATIENTS IN CENTRAL AND EASTERN EUROPE}

D. Opris-Belinski ${ }^{1}$, S. Erdes ${ }^{2}$, S. Grazio ${ }^{3}$, L. Šenolt ${ }^{4}$, M. Hojnik ${ }^{5}$, O. Nagy ${ }^{6}$, L. losub ${ }^{7}$, S. Szántó ${ }^{8} .{ }^{1}$ Rheumatology, Sf. Maria Clinical Hospital, Carol Davila University of Medicine, Bucharest, Romania; ${ }^{2}$ V. A. Nasonova Research Institute of Rheumatology, Moscow, Russian Federation; ${ }^{3}$ Univ. Dpt. of Rheumatology, Clinical Hospital Centre Sisters of Mercy, Croatia, Zagreb, Croatia; ${ }^{4}$ Dpt. of Rheumatology, 1st Faculty of Medicine, Charles Univ, Institute of Rheumatology, Prague, Czech Republic: ${ }^{5}$ AbbVie, Global Medical Affairs, Ljubliana, Slovenia; ${ }^{6}$ AbbVie, Global Medical Affairs, Budapest, Hungary; ${ }^{7}$ AbbVie, Global Medical Affairs, Bucharest, Romania; ${ }^{8}$ Rheumatology, Faculty of Medicine, Univ. of Debrecen, Debrecen, Hungary

Background: Ankylosing spondylitis (AS) represents a considerable socioeconomic burden due to early disease onset, development of functional disability and life-time costs. The impact of originator adalimumab on the extent of outpatient attendance, hospitalizations and sick leave in relation to clinical outcomes is not known in Central and Eastern Europe (CEE).

Objectives: To evaluate disease activity, physical function, selected health care resource utilization and sick leaves in patients treated with adalimumab in clinical practice in CEE countries.

Methods: This was a 52-week multi-center post-marketing observational study conducted in 5 countries in CEE. Eligible AS patients were prescribed originator adalimumab according to the local practice; 5 study visits $(\mathrm{V})$ were performed approx. 3 months apart. Disease activity was measured by Bath Ankylosing Spondylitis Disease Activity Index (BASDAI) and Ankylosing Spondylitis Disease Activity Index (ASDAS ${ }_{\text {CRP) }}$, treatment response as BASDAI50 and $\triangle A S D A S \geq-2$ (at study end), physical function by Bath Ankylosing Spondylitis Functional Index (BASFI). Data on AS related healthcare resource utilization and sick leave during the study was recorded prospectively through a systematic interview with the patient at each study visit. For pre-and post-treatment comparison, the same sort of data were recorded retrospectively at baseline visit for the 3-month period preceding adalimumab therapy, verified against chart review, then multiplied by 4 to match the prospective follow-up duration. Descriptive statistics were used; last observation carried forward data are presented herein.

Results: 452 patients were enrolled, 360 completed the study. Mean age was 42.9 ( \pm 12.1$)$ yrs; $68.7 \%$ were male and $62.7 \%$ were employed at baseline. Average disease duration was $7.7( \pm 8.7)$ yrs. Mean BASDAI and ASDAS decreased from $6.3( \pm 2.1)$ and $4.0( \pm 1.1)$ at baseline to $2.3( \pm 2.0)$ and $1.9( \pm 1.1)$ at study end, respectively; mean BASFI from $6.2( \pm 2.3)$ to $2.6( \pm 2.3)$. BASDAI and ASDAS based treatment response was seen at study end in $72.3 \%$ and $58.9 \%$ of patients, respectively. The mean number of hospital admissions and inpatient days decreased from $2.8( \pm 3.9)$ to $0.9( \pm 2.8)$ and from $23.0( \pm 40.8)$ to $3.9( \pm 17.7)$, respectively (pre- and post-treatment). The mean number of sick leaves and sick leave days decreased from $3.2( \pm 8.8)$ to $1.1( \pm 5.6)$ and from $32.2( \pm 69.2)$ to $5.1( \pm 24.5)$, respectively (employed patients only, $n=282$ ). The reduction of hospital admissions/days, sick leaves and sick leave days were higher in treatment responders compared to non-responders. No new safety signal was detected. Conclusions: Treatment with adalimumab in routine clinical practice in $5 \mathrm{CEE}$ countries resulted in clinically meaningful improvements in disease activity and physical function as well as reduced healthcare resource utilization and sick leaves.

Acknowledgements: The design, study conduct, and financial support for the 